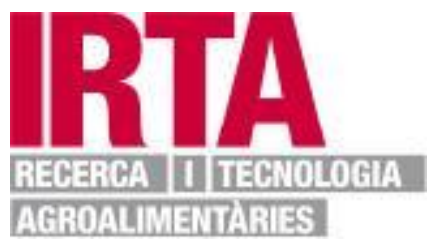

This document is a postprint version of an article published in Meat Science, copyright $\odot$ Elsevier B.V. after peer review.

To access the final edited and published work see:

http://dx.doi.org/10.1016/i.meatsci.2006.09.020 


\section{Assessment of High Hydrostatic Pressure and Starter Culture on the Quality Properties of Low-Acid Fermented Sausages}

Begonya Marcos, Teresa Aymerich, M. Dolors Guardia, Margarita Garriga*

Institute for Food and Agricultural Research and Technology (IRTA), Meat Technology Centre, Granja Camps i Armet s/n, 17121 Monells, Spain

\section{${ }^{*}$ Corresponding author.}

Institute for Food and Agricultural Research and Technology (IRTA), Meat Technology Centre, Granja Camps i Armet s/n, 17121 Monells, Spain.

Tel. + 34972630052

Fax. +34972630373

E-mail address: margarita.garriga@irta.es 


\section{Abstract}

The addition of starter culture and high pressure processing after ripening improved the microbial quality of low-acid fermented sausages (fuet and chorizo). The use of Lactobacillus sakei CTC6626 and Staphylococcus xylosus CTC6013 as starter culture significantly reduced Enterobacteriaceae and Enterococcus levels in the finished sausages. Moreover, the addition of starter culture produced sausages with similar quality properties to traditional low-acid fermented sausages. Slightly lower $\mathrm{pH}$ values and higher cohesiveness were obtained for both fuet and chorizo with starter culture. Sensory analysis showed no differences between lots of chorizo whereas starter fuet was more acid and gummy. High pressure induced an additional reduction of Enterobacteriaceae in non-starter sausages. An increase of texture properties was observed after pressurisation. No other differences were observed between non-treated and pressurized sausages.

Keywords: low-acid fermented sausages, traditional sausages, starter culture, high pressure processing 


\section{Introduction}

The consumption of low-acid fermented sausages, with a limited acid taste, is common among Mediterranean countries. Sausages are dried at low temperatures $\left(\leq 10-12^{\circ} \mathrm{C}\right)$ to avoid a rapid and intense fermentation, achieving final pH values of over 5.3 (Sanz, Vila, Toldrá, \& Flores, 1998; Aymerich, Martín, Garriga, \& Hugas, 2003). Many traditional slightly fermented sausages are produced by spontaneous meat fermentation, which cannot always guarantee the product to be safe and stable.

The addition of competitive starter cultures to lead the fermentation process is an effective method of inhibiting and/or controlling the growth of spoilage organisms and food-borne pathogens, preventing the formation of undesirable end-products (Rödel, Stiebing, \& Kröckel, 1993; Lücke, 1998; Garriga et al., 2005). In Europe, starter cultures are made-up of a balance between the two main groups of bacteria that are responsible for meat fermentation: lactic acid bacteria (Lactobacillus) and Grampositive catalase-positive cocci (Staphylococcus) (Hugas \& Monfort, 1997; Talon, Leroy-Sétrin, \& Fadda, 2002). Lactic acid bacteria (LAB) inhibit spoilage and pathogen development mainly as a result of competitive growth and acidification of the product. Acidification promotes the formation of colour and the cohesion of sausages (Lücke, 1998, 2000; Bacus, 1986). The addition of Gram-positive catalase-positive cocci $(\mathrm{GCC}+)$ to dry sausage manufacturing improves their sensorial properties (Nychas \& Arkoudelos, 1990). GCC+ contribute to the development of dry sausage flavour by influencing the composition of volatile compounds in the products. In particular, they modulate the level and nature of volatiles originated from lipid oxidation (Berdagué, Monteil, Montel, \& Talon, 1993; Montel, Reitz, Talon, Berdagué, \& Rousset-Akrim, 1996; Talon, Walter, \& Montel, 2000). GCC+ also ensure colour development by nitrate reductase activity (Lücke \& Hechelmann, 1987).

High pressure processing (HPP) is a preservation method that kills and/or sub-lethally injures microorganisms mainly owing to membrane damage (Kalchayanand, Sikes, Dunne, \& Ray, 1998). The pressure stability of vitamins and low molecular weight molecules, mainly responsible for odour and flavour (Smelt, 1998) makes this technology an interesting non-thermal alternative method to inactivate vegetative bacterial cells in RTE-foods. It is worth noting that besides destroying microorganisms there are further influences of pressure on food products to be expected, such as protein denaturation or modification, enzyme activation or inactivation, changes in enzyme-substrate interactions, changes in the properties of polymer carbohydrates and fats (Butz \& Tauscher, 2002) that could affect the final quality of fermented sausages. 
In a previous work (Garriga et al., 2005) the addition of starter culture consisting of LAB and GCC+ led to an improvement in safety and hygiene of low-acid fermented sausages inoculated with pathogens. However, pressurization proved to be necessary to assure absence of Salmonella spp. in the finished product.

The aim of this study was to evaluate the impact of the addition of a starter culture (consisting of selected strains of L. sakei and S. xylosus) and HPP on the microbial, chemical, physical and sensory properties of two types of traditional Spanish low-acid fermented sausages (fuet and chorizo).

\section{Materials and methods}

\subsection{Low-acid fermented sausage manufacture}

Two types of low-acid fermented sausages, fuet (F) and chorizo (C), were manufactured. Both products were made with pork bellies and shoulders. The meat was minced at $-1^{\circ} \mathrm{C}$ in a meat cutter (Tecmaq, Barcelona, Spain) with an adjustable plate set at a hole diameter of $6 \mathrm{~mm}$. A shoulder:belly proportion of 50:50 was mixed with common additives in a mixer machine (model 35P, Tecnotrip S.A., Terrassa, Spain). The formulation of fuet was as follows (g per $\mathrm{kg}$ ): sodium chloride 20, black pepper 2.5 , potassium nitrate 0.1 , sodium nitrite 0.1 , dextrose 1 , and sodium ascorbate 0.5 . The formulation of chorizo was ( $\mathrm{g}$ per $\mathrm{kg}$ ): sodium chloride 20 , cayenne pepper 15 , paprika 15 , dextrose 1 , and dehydrated garlic 3 . Two different lots of each product were manufactured: lot 1 , non-starter, and lot 2 , inoculated with a starter culture consisting of L. sakei CTC6626 and S. xylosus CTC6013. L. sakei and S. xylosus were inoculated to achieve $4 \times 10^{5}$ and $4 \times 10^{6} \mathrm{CFU} / \mathrm{g}$, respectively per sausage for each species. The mixture was stuffed in collagen casings (Colex 32 mm, Fibran S.A., Girona, Spain), each lot consisted of 28 sausages (350 g each sausage). Sausages were ripened at $12^{\circ} \mathrm{C}$ and $80 \%$ of relative humidity for 28 days.

\subsection{High pressure processing}

After 28 days of ripening, half of sausages were no-treated (HPP-) and half were subjected to a high pressure treatment (HPP+). After vacuum packaging in polyamide-polyethylene bags (Sacoliva, Sabadell, Spain), the sausages were pressurized at $400 \mathrm{MPa}$ for 10 minutes at $17^{\circ} \mathrm{C}$. HPP was carried out in an industrial hydrostatic pressurization unit (Alstom, France) with a chamber of 320 I volume and $280 \mathrm{~mm}$ diameter. The pressurization fluid was water, the come up time was $17.5 \mathrm{~min}$, the pressure release time was $1.5 \mathrm{~min}$, and the adiabatic heat generated was $5^{\circ} \mathrm{C}$. 


\subsection{Sampling procedure}

During the ripening process, at selected times $(0,6$ days), three individual sausages from each product $(F, C)$ and lot $(1,2)$ were sampled for microbial counts, $\mathrm{pH}$ and water activity $\left(\mathrm{a}_{\mathrm{w}}\right)$ determination. At the end of ripening (28 days), and after high pressure treatment three sausages from each product $(F, C)$, lot $(1,2)$, and pressure treatment (HPP-, HPP+) combinations were sampled for microbial counts, $\mathrm{pH}, \mathrm{a}_{\mathrm{w}}$, TBARS, colour and texture determination. For sensory analysis two individual sausages of each treatment combination were sampled.

\subsection{Microbiological analysis}

Twenty grams of sausage were 10 -fold diluted in sterile $0.1 \%$ peptone water (Difco Laboratories, Detroit, Mich., U.S.A.) and $0.85 \% \mathrm{NaCl}$ (Merck, Darmstadt, Germany). The solution was homogenized for $1 \mathrm{~min}$ in a Masticator (IUL Instruments, Barcelona, Spain). After appropriate dilutions, the following determinations were carried out: LAB were enumerated by pour plating in MRS agar (Merck, Darmstadt, Germany) incubated anaerobically at $30^{\circ} \mathrm{C}$ for $72 \mathrm{~h}$; GCC+ were enumerated by spread plating in mannitol salt agar, MSA (Difco Laboratories) incubated at $30^{\circ} \mathrm{C}$ for $48 \mathrm{~h}$; Enterococcus were enumerated in poured kanamycin-esculin-azide agar (Oxoid, Basingstoke, Hampshire, England) incubated at $37^{\circ} \mathrm{C}$ for $24 \mathrm{~h}$; Enterobacteriaceae were enumerated by pour plating in violet red bile glucose agar (Merck) at $30^{\circ} \mathrm{C}$ for $24 \mathrm{~h}$.

\subsection{Strain typing}

Twenty colonies of LAB and GCC+ per lot were randomly selected from the MRS and MSA agar plates respectively, and used for implantation control of starter cultures in the finished products. Total DNA isolation was performed as previously reported (Aymerich et al., 2003). To achieve the lysis of GCC+ cells, lysostaphin $(55 \mathrm{U} / \mathrm{ml})$ was added to the lysis step. Strain typing was assessed by random amplification of polymorphic DNA (RAPD) PCR as previously reported (Martín, Garriga, Hugas, \& Aymerich, 2005). Two random primers (Roche Molecular Biochemicals, Indianapolis, Ind.) were used for RAPD analysis, R5 (59-aacgcgcaac) and M13R2 (59-ggaaacagctatgaccatga). The banding profiles were visualized under UV light and digitalized by the Gelprinter photodocumentation equipment (TDI, Barcelona, Spain). Electrophoretic profiles obtained were normalized and analyzed by the software Fingerprinting II (Bio-Rad Laboratories, Hercules, Calif.). 


\section{6. $\mathrm{pH}$, water activity, nitrate and nitrite measurements}

The $\mathrm{pH}$ was measured directly in the samples using a Crison penetration 52-32 electrode connected to a Crison Basic $20 \mathrm{pH}$-meter (Crison Instruments S.A., Alella, Spain). The mean of three measurements was recorded for each sausage. Water activity $\left(a_{w}\right)$ measurement was carried out using a Novasina Thermoconstanter TH-500 (Novasina, Switzerland) at $25 \stackrel{\circ}{\circ}$.

Nitrate and nitrite contents were evaluated with a segmented continuous-flow Autoanalyzer II sampler (Technicon Ltd. Dublin, Ireland) by methods US-230-72A, as recommended by the manufacturer.

\subsection{Measurement of lipid oxidation}

The extent of lipid oxidation was measured as thiobarbituric acid reactive substances (TBARS). The extraction method used was based on the procedure of Botsoglow, et al. (1994). After mincing, a sample of $2.5 \mathrm{~g}$ was homogenized with $20 \mathrm{ml}$ of ultra pure water. Five $\mathrm{ml}$ of $25 \%$ trichloroacetic acid (Sigma-Aldrich, Saint Louis, MO, U.S.A.) were added to the homogenate. The solution was centrifuged at $4^{\circ} \mathrm{C}$ for $15 \mathrm{~min}$ at $13,000 \times \mathrm{g}$. After filtration, $3.5 \mathrm{ml}$ of the extract were incubated with $1.5 \mathrm{ml}$ of $0.6 \%$ aqueous 2-thiobarbituric acid (Sigma-Aldrich) for $30 \mathrm{~min}$ at $70^{\circ} \mathrm{C}$, and cooled with ice. The absorbance was measured at $532 \mathrm{~nm}$ using a UV-240 spectrophotometer (Shimadzu Corporation, Kyoto, Japan). The concentration was calculated using a standard curve of malonaldehyde (0-2,5ng) (Sigma-Aldrich). Stock MDA solution $(250 \mu \mathrm{gMDA} / \mathrm{ml})$ was obtained after hydrolysis of 1,1,3,3-tetraethoxypropane (TEP) in $10 \mathrm{ml}$ of $0.1 \mathrm{~N} \mathrm{HCl}$. The solution was immersed in a bath of boiling water for $5 \mathrm{~min}$ and quickly cooled. $1 \mathrm{ml}$ of hydrolyzed TEP was diluted to $250 \mathrm{ml}$ with ultrapure water. Results were expressed as micrograms of malonaldehyde (MDA) per gram of sausage.

\subsection{Instrumental colour measurement}

Instrumental colour measurements of sausages were performed using a Minolta Chromameter CR200 (Minolta, Japan). C illuminant and $2^{\circ}$ standard observer were chosen. L* (lightness), a* (redness), and $b^{*}$ (yellowness) colour values were determined in the 1976 CIELAB system. The colorimeter was calibrated before each series of measurements using a white ceramic plate. The mean of six measurements was recorded for each sausage. 


\subsection{Texture Profile Analysis (TPA)}

A MTS Texture Analyser (MTS Systems Corporation, MN, USA) was used to carry out a Texture Profile Analysis (TPA: Bourne, 1978) of the finished products. TPA is an imitative test that simulates 2 consecutive bites by way of two cycles of compression. The samples $(1 \times 1 \times 1 \mathrm{~cm})$ were compressed to $75 \%$ of their original height using a crosshead speed of $1 \mathrm{~mm} / \mathrm{s}$. The following parameters were determined: hardness $(\mathrm{Kg})$, cohesiveness (dimensionless), springiness (dimensionless), and chewiness $(\mathrm{Kg})$. The mean of six measurements per sausage was recorded.

\subsection{Sensory analysis}

Six trained assessors (ASTM, 1981) undertook the sensory analysis on $1 \mathrm{~cm}$ thick slices. The generation and selection of the descriptors was carried out by open discussion in three sessions. Both products were checked for appearance (colour intensity), odour (overall intensity, rancid), acid taste, flavour (rancid, cured, cooked, off-flavours) and texture (hardness, gumminess). A non-structured 10point scoring scale (Amerine, Pangborn, \& Roessler, 1965) was used, where 0 means absence or very low intensity of the descriptor and 10 means very high intensity of the descriptor. Means of scores given by the assessors for each sausage were recorded. Evaluation was undertaken in four sessions (two sessions per product). A randomized complete block design (Steel \& Torrie, 1983) was used in the sensory sessions, testing four sausages per session.

\subsection{Statistical analysis}

Data from each product (fuet and chorizo) were analysed separately using the GLM procedure from the SAS statistical package (SAS @ System for Windows, Release 8.2, SAS Institute, Cary, NC, USA).

The model for $\mathrm{pH}, \mathrm{a}_{\mathrm{w}}$, and microbiological data recorded during ripening $(0,6,28$ days) included lot, time, and their interaction as fixed effects. The model for $\mathrm{pH}, \mathrm{a}_{\mathrm{w}}$, microbiological, TBARS, instrumental colour, TPA, and sensory data recorded in the finished product included lot $(1,2)$, pressure treatment (HPP-, HPP+) and their interaction as fixed effects. Session was also added to the model as a fix effect for data from sensory analysis. Non significant interactions $(p>0.05)$ were dropped from the model. Differences were assessed by the tukey test $(p<0.05)$.

The percentage of implantation of a given inoculated strain was ascertained according to a sampling plan based on the binomial distribution (Peña Sánchez de Rivera, 1986). The implantation breakpoint, 
defined as percentage of strains that showed the same RAPD profile as the added starter cultures, was set up at $83 \%$.

\section{Results}

\subsection{Water activity, $\mathrm{pH}$, nitrate and nitrite content}

During ripening the water activity $\left(a_{w}\right)$ of sausages decreased $(p<0.05)$ from an initial value of $0.98 \pm 0.01$ in the raw product to values of $0.86-0.88$ at day 28 of ripening. No other significant effect on $a_{w}$ was observed.

Interactions between lot and time were significant for $\mathrm{pH}$ values, results of the interaction are shown in figure 1. No decrease of $\mathrm{pH}(\mathrm{p}>0.05)$ was observed during ripening of non-starter sausages (lot 1$)$, showing final values of $5.80 \pm 0.03$ and $5.71 \pm 0.01$ in $\mathrm{F} 1$ and $\mathrm{C} 1$, respectively. Oppositely, sausages inoculated with starter culture (lot 2) showed a pronounced decrease $(\mathrm{p}<0.05)$ of $\mathrm{pH}$ values during the first days of ripening, reaching minimum values at day 6 of process (Fig. 1).

No changes of $\mathrm{pH}$ and $\mathrm{a}_{\mathrm{w}}$ values ( $\mathrm{p}>0.05$ ) were observed as a consequence of pressurization (400 $\mathrm{MPa}$ ) of ripened sausages (Tables 1 and 2).

Fuet contained $100 \mathrm{ppm}$ of nitrate and $100 \mathrm{ppm}$ of nitrite as additives, whereas chorizo contained only $54 \mathrm{ppm}$ of nitrate and $0.38 \mathrm{ppm}$ of nitrite supplied by cayenne pepper and paprika.

\subsection{Microbiological analysis}

Interactions between lot and time were significant for microbiological data; results of the interaction are shown in figure 2. Initial LAB levels of $10^{5} \mathrm{CFU} / \mathrm{g}$ were observed in all lots, both non-starter and starter. Endogenous LAB (lot 1) grew gradually during the process, reaching values at the end of ripening of $7.25 \pm 0.10$ and $7.78 \pm 0.13 \log C F U / g$ in $F 1$ and $C 1$, respectively. LAB of starter sausages (lot 2), though, experienced a sharp increase in growth $(p<0.05)$, reaching counts of $9.25 \pm 0.48$ log CFU/g at day 6 , values that were maintained until the end of ripening (Fig. 2a). LAB levels of lot 2 were, thus, significantly higher than those of lot 1 throughout the process. Initial levels of endogenous $\mathrm{GCC}+$ were $3.51 \pm 0.18$ and $6.59 \pm 0.19 \log \mathrm{CFU} / \mathrm{g}$ in non-starter sausages (F1, C1), and starter sausages (F2, C2), respectively. No differences $(p>0.05)$ were found in $G C C+$ counts between $C 1$ and $\mathrm{C} 2$ at the end of ripening $(6.87 \pm 0.40 \log \mathrm{CFU} / \mathrm{g})$, whereas significantly higher counts $(p<0.05)$ were observed in F2 compared to $\mathrm{F} 1(7.87 \pm 0.24$ and $6.61 \pm 0.20 \mathrm{log} C F U / g$, respectively). Implantation of 
inoculated starter cultures was monitored by RAPD PCR. At the end of ripening $100 \%$ of GCC+ isolates presented identical fingerprints to S. xylosus CTC6013 in F2, whereas it represented $65 \%$ of isolates in C2. Among LAB isolates, 100\% yielded the L. sakei CTC6626 genotype both in F2 and C2.

Figure $2 \mathrm{~b}$ shows the evolution of Enterobacteriaceae population during ripening. In non-starter sausages Enterobacteriaceae counts increased in 2.6 log units during the first 6 days. These levels (5 $\log \mathrm{CFU} / \mathrm{g}$ ) were maintained until the end of ripening in $\mathrm{C} 1$, whereas they were reduced to initial counts in F1. In starter sausages F2 showed no growth of Enterobacteriaceae during the first 6 days of ripening, while C2 showed an increase of 2.5 log units. All starter sausages attained Enterobacteriaceae counts under the detection limit (10 CFU/g) at the end of ripening. Enterococcus counts of non-starter sausages increased $(\mathrm{p}<0.05)$ during the process in 2.1 and 2.8 log units in F1 and $\mathrm{C} 1$, respectively. By contrast, enterococcal population of starter sausages decreased 1 logarithm $(p<0.05)$ during ripening (Fig. $2 c)$.

Interaction between lot and pressure treatment was significant, for GCC+, and Enterobacteriaceae data in both products, for LAB data in fuet, and for Enterococcus data in chorizo. For LAB counts pressurization only reduced the counts $(p<0.05$ ) of $F 1$ (from $7.25 \pm 0.10$ to $6.42 \pm 0.28 \log C F U / g$ ). On the other hand, after pressurization, GCC+ levels in F2 (7.87 $\pm 0.24 \log$ CFU/g) and C2 $(7.44 \pm 0.39 \log$ CFU/g) were significantly reduced in 0.83 and $0.92 \log \mathrm{CFU} / \mathrm{g}$, respectively. Regarding Enterobacteriaceae population, HPP reduced the counts $(\mathrm{p}<0.05)$ of $\mathrm{F} 1(1.98 \pm 0.52 \log \mathrm{CFU} / \mathrm{g})$ and C1 $(4.74 \pm 0.01 \log \mathrm{CFU} / \mathrm{g})$ in 1 and 3.8 logarithms, respectively, both reaching counts under the detection limit. For Enterococcus counts pressurisation only reduced the counts $(p<0.05)$ of $C 1$ (from $5.39 \pm 0.35$ to $3.35 \pm 0.38 \log \mathrm{CFU} / \mathrm{g})$.

\subsection{Lipid oxidation: TBARS}

Interaction between lot and pressure treatment was not significant $(p>0.05)$. Tables 1 and 2 show TBARS values of fuet and chorizo after 28 days of ripening. No significant effect $(p>0.05)$ was observed as a consequence of either addition of starter culture or pressure treatment.

\subsection{Instrumental colour analysis}

Interaction between lot and pressure treatment was not significant $(p>0.05)$. Colour parameters of lowacid fermented sausages at the end of processing are presented in Tables 1 and 2. No significant differences were observed among lots of fuet (Table 1). The addition of starter culture to chorizo (C2) 
led to sausages with higher $\mathrm{a}^{*}$ (redness) values than in the control lot, C1 (Table 2). None of the colour parameters of fuet and chorizo were modified by pressurization at $400 \mathrm{MPa}$.

\subsection{Texture Profile Analysis (TPA)}

Interaction between lot and pressure treatment was not significant $(p>0.05)$. The results of the TPA applied to fuet and chorizo after 28 days of ripening are shown in Tables 1 and 2. Higher values of cohesiveness $(p<0.05)$ were observed in starter sausages (lot 2$)$ than in non-starter ones (lot 1$)$. F2 showed higher values of chewiness and springiness $(p<0.05)$ than $F 1$. Pressurization of sausages at $400 \mathrm{MPa}$ increased $(\mathrm{p}<0.05)$ the cohesiveness, chewiness and springiness of both fuet and chorizo (Tables 1 and 2).

\subsection{Sensory analysis}

Interaction between lot and pressure treatment was not significant $(p>0.05)$. Results of the sensory analysis of ripened fuet and chorizo are shown in Tables 3 and 4, respectively. The trained assessors detected higher colour intensity and stronger cured flavour in $\mathrm{C} 1$ than in $\mathrm{C} 2$. Besides, starter fuet (F2) were scored with higher acid taste and gummier texture than control fuet (F1). Pressurization induced no changes $(p>0.05)$ in the sensory properties of fuet, while a slight decrease $(p<0.05)$ of colour intensity was detected by the assessors in pressurized chorizo. 


\section{Discussion}

\section{Effect of starter culture}

In the manufacture of low-acid fermented sausages, the selection of the appropriate strains used as starter cultures becomes essential to obtain products with the characteristic quality attributes of the traditional products.

The addition of starter culture, L. sakei CTC6626, which dominated over endogenous LAB, assured the $\mathrm{pH}$ drop in fuet and chorizo. Nevertheless, all sausages studied presented final $\mathrm{pH}$ values $\geq 5.3$, which are common values for this type of low-acid fermented sausages (Sanz et al., 1998; Aymerich et al., 2003). Starter sausages led to a decrease of Enterobacteriaceae population below the detection limit. However, its growth during the first days of ripening could only be prevented in starter fuet, probably due to the highest content of nitrate and nitrite. Besides, the addition of the starter culture led to the reduction of Enterococcus levels during ripening of starter lots. The control of this population by starter cultures seemed to be more related to competitive exclusion than to $\mathrm{pH}$, since enterococci are considered highly resistant to extreme pH values (Giraffa, 2002; Garriga et al., 2005). The control of Enterobacteriaceae and Enterococcus growth throughout the process is essential to prevent quality defects such as the formation of off-flavours and the production of biogenic amines (Maijala, Eerola, Lievonen, Hill, \& Hirvi, 1995; Garriga et al., 1996), therefore the combination of hurdles proved to be necessary to improve the microbial quality of the product.

GCC+ influence the quality of the product by contributing to the oxidation of free fatty acids and colour formation during ripening. Oxidation is necessary to develop the desirable flavour of fermented sausages, but it is also one of the primary mechanisms of quality deterioration (Madsen \& Bertelsen, 1995; Aguirrezábal, Mateo, Domínguez, \& Zumalacárregui, 2000). No differences on TBARS values, used as a measure of lipid oxidation, were observed between lots coinciding with low values of rancidity observed in the sensory analysis. Love \& Pearson (1974) related TBARS numbers greater than 1.0 to the detection of off-flavours, however no off-flavours were detected in our study in samples with TBARS values in a range of 1 to 2 . No colour differences were found among lots of fuet, it can be deduced that both endogenous and inoculated GCC+ influenced colour formation in the same way, leading to end products with similar colour parameters. However, in chorizo lower $\mathrm{a}^{*}$ values were observed in non-inoculated lot. Fernández-López, Pérez-Álvarez, Sayas-Barberá, \& López-Santoveña (2002) suggested that a decrease of $a^{*}$ in chorizo could reflect an incipient oxidation of paprika. 
The addition of starter culture affected textural characteristics of fermented sausages, it might be due mainly to their proteolytic activity and differences in $\mathrm{pH}$ values of sausages. Starter sausages, which were more acid than non-starter, showed higher cohesiveness, chewiness and springiness in fuet and higher values of cohesiveness in chorizo. Thus, the values of the textural properties increased as the $\mathrm{pH}$ values of sausages came near to the isoelectric point of meat proteins (5.3). Gimeno, Ansorena, Astiasarán, \& Bello (2000) reported negative correlations of cohesiveness, chewiness and hardness with $\mathrm{pH}$ values in chorizo. In the sensory analysis, the assessors found starter fuet gummier than non-starter ones. The increased sensory gumminess could be related to the higher instrumental springiness detected by the TPA.

\section{Effect of high pressure processing}

High pressure processing (400 MPa) at the end of ripening reduced Enterobacteriaceae population of non-starter sausages. Besides, Enterococcus levels were reduced in non-starter chorizo, confirming the fact that sensitivity of enterococcal population to HPP presents a great variability influenced by the numbers and spices composition of each specific product (Martín et al., 2005).

No changes of colour parameters were observed after pressurization of fermented sausages. The ripening process leads to colour stabilitzation by turning myoglobin into nitrosylmyoglobin and nitrosylhaemochrome, which are not affected by pressure (Carlez et al., 1995; Cheftel \& Culioli, 1997). Goutefongea, Rampon, Nicolas, \& Dumont (1995) also reported no changes in $\mathrm{a}^{*}$ and $\mathrm{b}^{*}$ values after pressurization of cured meat at $600 \mathrm{MPa}$, while $\mathrm{L}^{*}$ component was increased. However, a slight decrease of colour intensity in pressurized chorizo with respect to non-treated ones was detected in the sensory analysis. Anyway, it should be underlined that the difference detected by the trained panel ( 0.3 point difference), rarely could be detected by consumers. No alteration of TBARS values was detected in the present study, probably due to the fact that most lipid oxidation had already occurred during ripening. Andrés, Adamsen, Moller, Ruiz, \& Skibsted (2005) reported a loss of oxidative stability of dry-cured ham pressurized at $400 \mathrm{MPa}$, during subsequent air-storage.

Pressurized sausages showed higher cohesiveness, chewiness and springiness than non-treated sausages. Yuste, Mor-Mur, Capellas, \& Pla (1999) and Mor-Mur \& Yuste (2003) also observed an increase of cohesiveness in sausages treated at $500 \mathrm{MPa}$ at $65^{\circ} \mathrm{C}$. No texture changes induced by HPP were detected by the assessors, suggesting that its effect would not be detectable by consumers. 


\section{Conclusions}

Although starter cultures have proved to be important in improving hygiene and safety, the selection of optimum starter cultures that do not modify sensorial properties of traditional slightly fermented sausages is essential. The addition of starter culture (L. sakei CTC6626 and S. xylosus CTC6013) produced sausages with improved hygiene and similar quality properties to traditional low-acid fermented sausages.

High pressure processing $\left(400 \mathrm{MPa}, 17^{\circ} \mathrm{C}, 10 \mathrm{~min}\right)$ after ripening also improved hygiene of sausages, without damaging the quality of the product. Considering those results and the fact that this pressure treatment is effective in improving product safety (Marcos, Aymerich, \& Garriga 2005; Garriga et al., 2005), the use of high pressure treatment can be recommended as a final step in the manufacturing process of low-acid fermented sausages with appropriate starter cultures.

\section{Acknowledgements}

This work was supported by the National Institute for Food and Agricultural Research (INIA) projects RTA 01-084 and CPE 03-012-C3. B. Marcos is recipient of a pre-doctoral grant awarded by INIA. We thank L. Guerrero for his technical support in the sensory analysis.

\section{References}

Aguirrezábal, M. M., Mateo, J., Domínguez, M. C., \& Zumalacárregui, J. M. (2000). The effect of paprika, garlic and salt on rancidity in dry sausages. Meat Science, 54(1), 77-81.

American Society for Testing and Materials. (1981). Guidelines for the selection and training of sensory panel members. STP 758. Philadelphia: ASTM.

Amerine, M., Pangborn, R., \& Roessler, E. (1965). Principles of sensory evaluation of food. New York: Academic Press.

Andrés, A.I., Adamsen, C.E., Moller, J.K.S., Ruiz, J., Skibsted, L.H. (2005). High-pressure treatment of dry-cured Iberian ham. Effect on colour and oxidative stability during chill storage packed in modified atmosphere. European Food Research Technology, 222(5-6), 486-491.

Aymerich, M. T., Martín, B., Garriga, M., \& Hugas, M. (2003). Microbial quality and direct PCR identification of lactic acid bacteria and nonpathogenic staphylococci from artisanal low-acid sausages. Applied and Environmental Microbiology, 69(8), 4583-4594.

Bacus, J. N. (1986). Fermented meat and poultry products. In A. M. D. Pearson, T.R. (Ed.), Advances in Meat and Poultry Microbiology (pp. 123-164). London: Macmillan.

Berdagué, J. L., Monteil, P., Montel, M. C., \& Talon, R. (1993). Effect of Starter Cultures on the Formation of flavour Compounds in Dry Sausage. Meat Science, 35(3), 275-287. 
Botsoglow, N. A., Fletuoris, D. J., Papageorgiu, G. E., Vassilopoulos, V. N., Mantis, A. J., \& Trakatellis, A. G. (1994). Rapid, sensitive and specific thiobarbituric acid method for measuring lipid peroxidation in animal tissue, food and feedstuff samples. Journal of Agricultural and Food Chemistry, 42, 1931-1937.

Bourne, M. C. (1978). Texture profile analysis. Food Technology, 32, 62-66, 72.

Butz, P., \& Tauscher, B. (2002). Emerging technologies: chemical aspects. Food Research International, 35, 279-284.

Carlez, A., Veciana-Nogués, M. T., \& Cheftel, J. C. (1995). Changes in colour and myoglobin of minced meat due to high pressure processing. Lebensmittel-Wissenschaft und-Technologie, 28 , 528-538.

Cheftel, J. C., \& Culioli, J. (1997). Effects of high pressure on meat: a review. Meat Science, 46(3), 211-236.

Fernández-López, J., Pérez-Álvarez, J. A., Sayas-Barberá, M. E., \& López-Santoveña, F. (2002). Effect of paprika (Capsicum anuum) on color of Spanish-type sausages during the resting stage. Journal of Food Science, 67(6), 2410-2414.

Garriga, M., Hugas, M., Gou, P., Aymerich, M. T., Arnau, \& J., Monfort, J. M. (1996). Technological and sensorial evaluation of Lactobacillus strains as starter cultures in fermented sausages. International Journal of Food Microbiology, 32, 173-183.

Garriga, M., Marcos, B., Martín, B., Veciana-Nogués, M. T., Bover-Cid, S., Hugas, M., \& Aymerich, M. T. (2005). Starter cultures and high pressure processing to improve the hygiene and safety of slightly fermented sausages. Journal of Food Protection, 68(11), 2341-2348.

Gimeno, O., Ansorena, D., Astiasarán, I., \& Bello, J. (2000). Characterization of chorizo de Pamplona: instrumental measurements of colour and texture. Food Chemistry, 69(2), 195-200.

Giraffa, G. (2002). Enterococci from foods. FEMS Microbiology Reviews, 26, 163-171.

Goutefongea, R., Rampon, V., Nicolas, J., \& Dumont, J. P. (1995). Meat color changes under high pressure treatment. In Proceedings 41th International Congress of Meat Science and Technology, San Antonio, Texas.

Hugas, M., \& Monfort, J. M. (1997). Bacterial starter cultures of food fermentation. Food Chemistry, 59(4), 547-554.

Kalchayanand, N., Sikes, A., Dunne, C. P., \& Ray, B. (1998). Factors influencing death and injury of foodborne pahogens by hydrostatic pressure-pasteurization. Food Microbiology, 15(2), 207-214.

Love, J. D., \& Pearson, A. M. (1974). Metmyoglobin and nonheme iron as prooxidants in cooked meat. Journal Agricultural and Food Chemistry, 22, 1032.

Lücke, F. K., \& Hechelmann, H. (1987). Starter cultures for dry sausages and raw ham. Fleischwirtschaft, 67, 307-314.

Lücke, F. K. (1998). Fermented sausages. In B. J. B. Wood (Ed.), Microbiology of Fermented Foods (vol. 2, pp. 441-483). London: Blackie Academic \& Professional.

Lücke, F. K. (2000). Utilization of microbes to process and preserve meat. Meat Science, 56(2), 105115.

Madsen, H. L., \& Bertelsen, G. (1995). Species as antioxidants. Trends in Food Science and Technology, 6, 271-277. 
Maijala, R., Eerola, S., Lievonen, S., Hill, P., \& Hirvi, T. (1995). Formation of biogenic amines during fermentation of dry sausages as affected by starter culture an thawing time of raw materials. Journal of Food Science, 60(6), 1187-1190.

Marcos, B., Aymerich, T., \& Garriga, M. (2005). Evaluation of high pressure processing as an additional hurdle to control Listeria monocytogenes and Salmonella enterica in low-acid fermented sausages. Journal of Food Science, 70(7), 339-344.

Martín, B., Garriga, M., Hugas, M., \& Aymerich, T. (2005). Genetic diversity and safety aspects of enterococci from slightly fermented sausages. Journal of Applied Microbiology, 98(5), 1177-1190.

Montel, M. C., Reitz, J., Talon, R., Berdagué, J. L., \& Rousset-Akrim, S. (1996). Biochemical activities of Micrococcaceae and their effects on the aromatic profiles and odours of a dry sausage model. Food Microbiology, 13(6), 489-499.

Mor-Mur, M., \& Yuste, J. (2003). High pressure processing applied to cooked sausage manufacture: physical properties and sensory analysis. Meat Science, 65(3), 1187-1191.

Nychas, G. J. E., \& Arkoudelos, J. S. (1990). Staphylococci: their role in fermented sausages. Journal of Applied Bacteriology Symposium Supplement, 167S-188S.

Peña Sánchez de Rivera, D. (1986). Estadística. Modelos y métodos, 1. Fundamentos. Alianza Editorial, Madrid.

Rödel, W., Stiebing, A., \& Kröckel, L. (1993). Ripening parameters for traditional dry sausages with a mould covering. Fleischwirtschaft, 73, 848-853.

Sanz, Y., Vila, R., Toldrá, F., \& Flores, J. (1998). Effect of nitrate and nitrite curing salts on microbial changes and sensory quality of non-fermented sausages. International Journal of Food Microbiology, 42(3), 213-217.

Smelt, J. P. P. M. (1998). Recent advances in the microbiology of high pressure processing. Trends in Food Science and Technology, 9, 152-158.

Sorensen, B. B. (1997). Lipolysis of pork fat by the meat sarter culture Staphylococcus xylosus at various environmental conditions. Food Microbiology, 14(2), 153-160.

Steel, R. G. D., \& Torrie, J. H. (1983). Principles and procedures of statistics. New York: Mc Graw-Hill.

Talon, R., Walter, D., \& Montel, M. C. (2000). Growth and effect of staphylococci and lactic acid bacteria on unsaturated free fatty acids. Meat Science, 54(1), 41-47.

Talon, R., Leroy-Sétrin, S., \& Fadda, S. (2002). Bacterial starters involved in the quality of fermented meat products. In F. Toldrá (Ed.), Research advances in the quality of meat and meat products (pp. 175-191). Burjassot, Spain: Research Signpost.

Yuste, J., Mor-Mur, M., Capellas, M., \& Pla, R. (1999). Pressure- vs. heat-induced bacterial stress in cooked poultry sausages: a preliminary study. Letters in Applied Microbiology, 29, 233-237. 


\section{Figure captions}

Figure 1. Evolution of $\mathrm{pH}$ during ripening of fuet $(\mathrm{F})$ and chorizo $(\mathrm{C})$, non-starter (1), and inoculated with starter culture (2). Values are the mean of triplicate sausages.

Figure 2. Evolution of lactic acid bacteria (a), Enterobacteriaceae (b) and Enterococcus (c) population during ripening of fuet $(F)$ and chorizo (C), non-starter (1), and inoculated with starter culture (2). Values are the mean of triplicate sausages. 
Table 1. $\mathrm{pH}, \mathrm{a}_{\mathrm{w}}$, TBARS colour and texture profile analysis (TPA) parameters of fuet measured at the end of ripening (day 28).

\begin{tabular}{|c|c|c|c|c|c|}
\hline & \multicolumn{2}{|c|}{ Lot } & \multicolumn{2}{|c|}{ Treatment } & \multirow{2}{*}{ Root MSE } \\
\hline & $\begin{array}{c}1 \\
(n=6)\end{array}$ & $\begin{array}{c}2 \\
(n=6) \\
(n+1)\end{array}$ & $\begin{array}{l}\text { HPP- } \\
(\mathrm{n}=6)\end{array}$ & $\begin{array}{l}\mathrm{HPP}+ \\
(\mathrm{n}=6)\end{array}$ & \\
\hline aw & 0.858 & 0.878 & 0.862 & 0.874 & 0.0167 \\
\hline $\mathrm{pH}$ & $5.79^{a}$ & $5.53^{b}$ & 5.67 & 5.64 & 0.0431 \\
\hline$L^{*}$ & 39.19 & 40.34 & 39.33 & 40.21 & 2.6321 \\
\hline$a^{*}$ & 10.39 & 10.74 & 10.59 & 10.54 & 1.5373 \\
\hline$b^{*}$ & 3.26 & 3.26 & 3.34 & 3.17 & 0.6400 \\
\hline Cohesiveness & $0.151^{b}$ & $0.178^{a}$ & $0.152^{y}$ & $0.177^{x}$ & 0.0102 \\
\hline Hardness (Kg) & 12.12 & 11.80 & 11.20 & 12.71 & 2.8059 \\
\hline Chewiness $(\mathrm{Kg})$ & $0.449^{b}$ & $0.628^{a}$ & $0.395^{y}$ & $0.681^{x}$ & 0.1218 \\
\hline Springiness & $0.231^{b}$ & $0.291^{a}$ & $0.224^{y}$ & $0.298^{x}$ & 0.0198 \\
\hline $\begin{array}{r}\text { TBARS } \\
(\mu \mathrm{g} \mathrm{MDA} / \mathrm{Kg})\end{array}$ & 1.96 & 1.69 & 0.92 & 1.77 & 0.6856 \\
\hline
\end{tabular}

a,b different letters indicate significant differences between lots.

${ }^{x, y}$ different letters indicate significant differences between treatments.

1: non-starter; 2: inoculated starter culture.

HPP-: non-treated; HPP+: pressurized. 
Table 2. $\mathrm{pH}, \mathrm{a}_{\mathrm{w}}$, TBARS colour and texture profile analysis (TPA) parameters of chorizo measured at the end of ripening (day 28).

\begin{tabular}{|c|c|c|c|c|c|}
\hline & \multicolumn{2}{|c|}{ Lot } & \multicolumn{2}{|c|}{ Treatment } & \multirow{2}{*}{ Root MSE } \\
\hline & $\begin{array}{c}1 \\
(n=6)\end{array}$ & $\begin{array}{c}2 \\
(n=6)\end{array}$ & $\begin{array}{l}\text { HPP- } \\
(n=6)\end{array}$ & $\begin{array}{c}\mathrm{HPP}+ \\
(\mathrm{n}=6)\end{array}$ & \\
\hline aw & 0.859 & 0.854 & 0.856 & 0.857 & 0.0129 \\
\hline $\mathrm{pH}$ & $5.73^{\mathrm{a}}$ & $5.33^{b}$ & 5.50 & 5.56 & 0.0271 \\
\hline$L^{*}$ & 36.55 & 37.21 & 36.53 & 37.23 & 1.3944 \\
\hline$a^{*}$ & $13.74^{b}$ & $14.83^{a}$ & 14.15 & 14.41 & 0.5767 \\
\hline$b^{*}$ & 9.84 & 10.90 & 10.39 & 10.35 & 0.8613 \\
\hline Cohesiveness & $0.184^{b}$ & $0.197^{\mathrm{a}}$ & $0.182^{y}$ & $0.199^{x}$ & 0.0086 \\
\hline Hardness $(\mathrm{Kg})$ & 12.34 & 13.08 & 12.06 & 13.35 & 1.6707 \\
\hline Chewiness $(\mathrm{Kg})$ & 0.592 & 0.676 & $0.589^{y}$ & $0.739^{x}$ & 0.0958 \\
\hline Springiness & 0.254 & 0.261 & $0.237^{y}$ & $0.278^{x}$ & 0.0161 \\
\hline $\begin{array}{r}\text { TBARS } \\
(\mu \mathrm{g} \mathrm{MDA} / \mathrm{Kg})\end{array}$ & 1.21 & 1.02 & 0.46 & 0.80 & 0.2616 \\
\hline
\end{tabular}

a,b, different letters indicate significant differences between lots.

${ }^{x, y}$ different letters indicate significant differences between treatments. 1: non-starter; 2 : inoculated starter culture. HPP-: non-treated; HPP+: pressurized. 
Table 3. Sensory properties of fuet evaluated at the end of ripening (day 28).

\begin{tabular}{|c|c|c|c|c|c|}
\hline & \multicolumn{2}{|c|}{ Lot } & \multicolumn{2}{|c|}{ Treatment } & \multirow{2}{*}{ Root MSE } \\
\hline & $\begin{array}{c}1 \\
(\mathrm{n}=4)\end{array}$ & $\begin{array}{c}2 \\
(n=4)\end{array}$ & $\begin{array}{l}\text { HPP- } \\
(\mathrm{n}=4)\end{array}$ & $\begin{array}{l}\mathrm{HPP}+ \\
(\mathrm{n}=4)\end{array}$ & \\
\hline Colour intensity & 6.2 & 5.9 & 6.1 & 6.0 & 0.3573 \\
\hline Odour intensity & 5.0 & 5.1 & 5.2 & 4.9 & 0.5665 \\
\hline Rancid odour & 0.9 & 1.6 & 1.3 & 1.2 & 0.4071 \\
\hline Acid taste & $0.9^{b}$ & $3.0^{\mathrm{a}}$ & 1.9 & 2.0 & 0.3451 \\
\hline Cooked flavour & 0.3 & 0.6 & 0.1 & 0.7 & 0.3723 \\
\hline Rancid flavour & 1.1 & 1.3 & 0.9 & 1.5 & 0.5809 \\
\hline Off-flavours & 0.2 & 0.4 & 0.2 & 0.4 & 0.3140 \\
\hline Hardness & 3.9 & 3.6 & 3.7 & 3.8 & 0.6382 \\
\hline Gumminess & $1.3^{\mathrm{b}}$ & $2.3^{a}$ & 1.8 & 1.9 & 0.4439 \\
\hline
\end{tabular}

a,b different letters indicate significant differences between lots.

${ }^{x, y}$ different letters indicate significant differences between treatments.

1: non-starter; 2 : inoculated starter culture.

HPP-: non-treated; HPP+: pressurized. 
Table 4. Sensory properties of chorizo evaluated at the end of ripening (day 28).

\begin{tabular}{|c|c|c|c|c|c|}
\hline & \multicolumn{2}{|c|}{ Lot } & \multicolumn{2}{|c|}{ Treatment } & \multirow{2}{*}{ Root MSE } \\
\hline & $\begin{array}{c}1 \\
(n=4)\end{array}$ & $\begin{array}{c}2 \\
(n=4)\end{array}$ & $\begin{array}{l}\text { HPP- } \\
(\mathrm{n}=4)\end{array}$ & $\begin{array}{l}\mathrm{HPP}+ \\
(\mathrm{n}=4)\end{array}$ & \\
\hline Colour intensity & $8.1^{a}$ & $7.4^{b}$ & $7.9^{x}$ & $7.6^{y}$ & 0.1408 \\
\hline Odour intensity & 6.0 & 5.9 & 5.6 & 6.3 & 0.3112 \\
\hline Rancid odour & 0.4 & 0.2 & 0.3 & 0.3 & 0.2813 \\
\hline Acid taste & 1.2 & 2.5 & 1.7 & 2.0 & 0.7681 \\
\hline Cured flavour & $2.6^{\mathrm{a}}$ & $1.9^{b}$ & 2.1 & 2.4 & 0.1876 \\
\hline Rancid flavour & 0.2 & 0.5 & 0.4 & 0.4 & 0.4102 \\
\hline Off-flavours & 0.3 & 0.2 & 0.2 & 0.3 & 0.2633 \\
\hline Hardness & 4.4 & 3.9 & 4.1 & 4.1 & 0.8071 \\
\hline Gumminess & 1.5 & 2.0 & 1.6 & 1.8 & 0.5160 \\
\hline
\end{tabular}

${ }^{a, b}$ different letters indicate significant differences between lots.

${ }^{x, y}$ different letters indicate significant differences between treatments.

1: non-starter; 2: inoculated starter culture.

HPP-: non-treated; HPP+: pressurized. 
Figure 1.

509

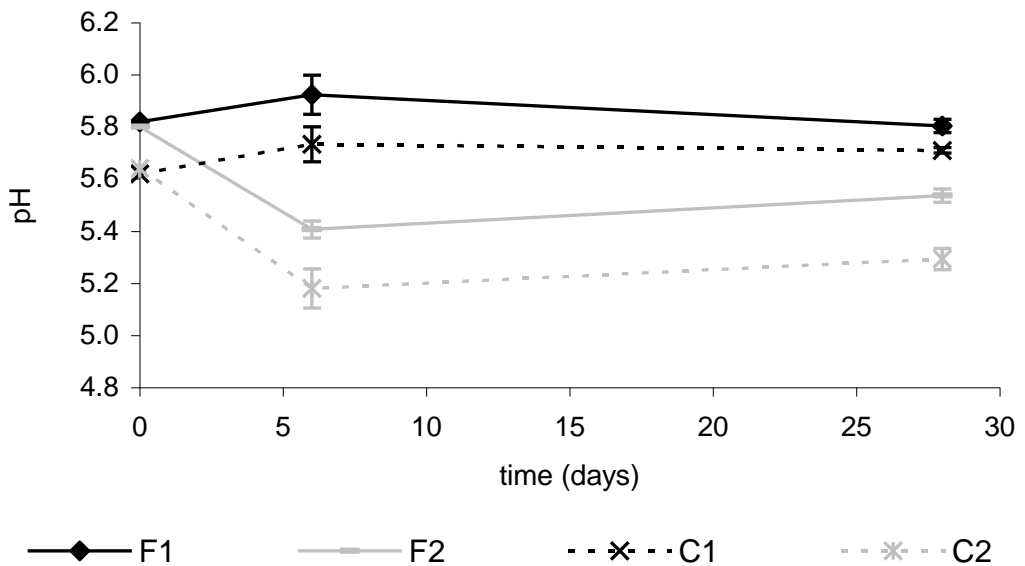

Figure 2.

513

a)

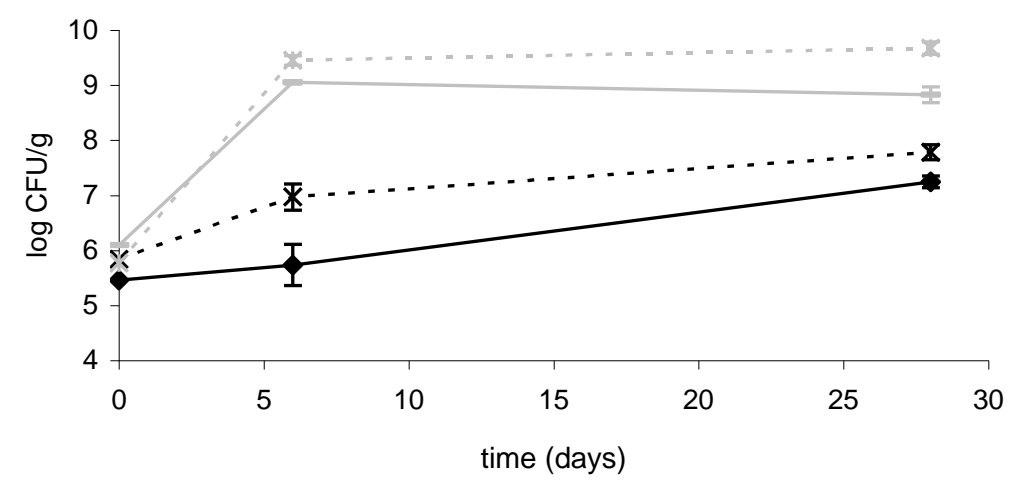

$\smile \mathrm{F} 1$

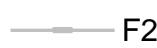

$--x-\cdot C 1$ 
b)
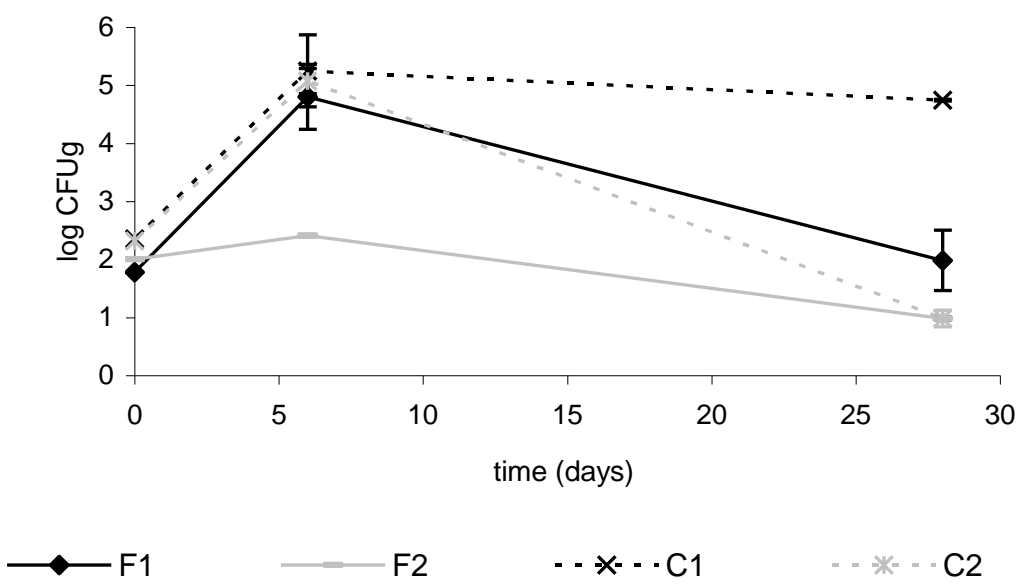

F2

$--x-\cdot C 1$

c)

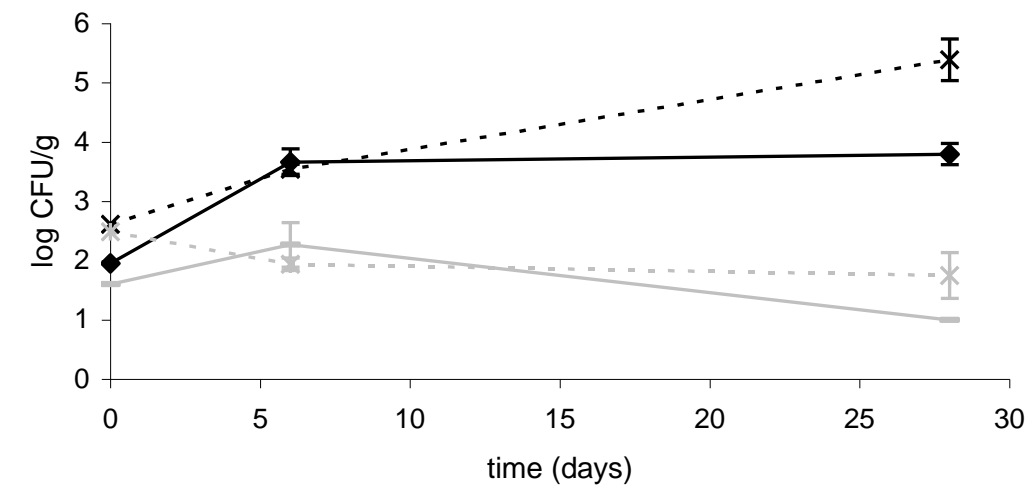

$\longrightarrow$ F1

$--x-\cdots C 1$

C2 